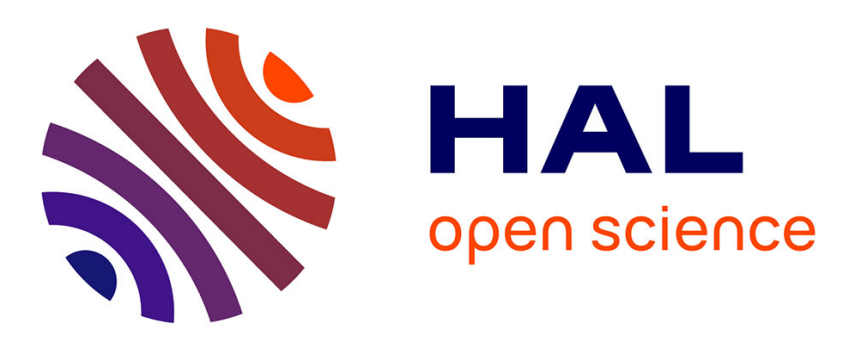

\title{
La frontière démultipliée ou les origines de la Question d'Andorre
}

Roland Viader

\section{To cite this version:}

Roland Viader. La frontière démultipliée ou les origines de la Question d'Andorre. Revue Europeenne des Migrations Internationales, 1998, 13 (3), pp.157-181. halshs-00195882

\section{HAL Id: halshs-00195882 \\ https://shs.hal.science/halshs-00195882}

Submitted on 11 Dec 2007

HAL is a multi-disciplinary open access archive for the deposit and dissemination of scientific research documents, whether they are published or not. The documents may come from teaching and research institutions in France or abroad, or from public or private research centers.
L'archive ouverte pluridisciplinaire HAL, est destinée au dépôt et à la diffusion de documents scientifiques de niveau recherche, publiés ou non, émanant des établissements d'enseignement et de recherche français ou étrangers, des laboratoires publics ou privés. 


\title{
La frontière démultipliée ou les origines de la Question d'Andorre
}

\author{
Roland Viader
}

« Peut-on, en effet, rien imaginer de plus absurde qu'un pays géré par deux souverains $[\ldots]$ ? $\gg^{1}$

«Il faudrait choisir ; M. Baudon de Mony n'a pas la prétention d'avoir défendu les droits de la France ; si donc il a voulu faire œuvre pratique et utile ce ne peut être qu'en faveur de l'évêché d'Urgell »². Pour Jean-Auguste Brutails, le débat est ainsi clarifié, d'autant que Charles Baudon de Mony «collabore aux publications anti-françaises du professeur barcelonais [M. Trias] $]^{3} »$. Mais Brutails y veille ; «les adversaires de la France en Andorre pourront parfois peut-être réussir, en fait, à réaliser ces projets de suprématie dont ils poursuivent le triomphe avec une rare ténacité. Ils seront moins heureux le jour où les expédients ne suffiront plus et où on s'avisera de discuter, au double point de vue de l'histoire et du droit, la légitimité de leurs prétentions $»^{4}$.

Ces lignes rédigées à la fin du XIX ${ }^{\mathrm{e}}$ siècle illustrent à merveille la pensée du futur auteur de La Coutume d'Andorre ${ }^{5}$. Mais, dans le même temps, elles disent avec force bien des éléments à l'œuvre dans la construction des frontières, et signalent implicitement toute la singularité du cas andorran.

On doit, pour l'apprécier, noter la rhétorique implacable qui condamne le contradicteur: tout ce qui ne défend pas les intérêts de la France l'agresse forcément ; en somme, Français ou anti-Français, « il faudrait choisir ». Mais sur le terrain andorran, comme Brutails avait pu le découvrir en Roussillon ${ }^{6}$, il existe des distorsions «en fait», des projets qui se réalisent. L'Andorre dont il traite

\footnotetext{
${ }^{1}$ J. D. TRIAS, Constitución política i personalidad internacional del principado de Andorra, Barcelona, 1890, p. 34; cité et traduit dans J.-A. BRUTAILS, «Etude critique sur les origines de la question d'Andorre ", Revue des Pyrénées, 1891, p. 991.

${ }^{2}$ J.-A. BRUTAILS, «Etudes critiques sur les origines de la question d'Andorre. Réponse à M. Baudon de Mony », Revue des Pyrénées, 1892, 577.

${ }^{3}$ Ibidem, p. 579.

${ }^{4}$ J.-A. BRUTAILS, « Etude critique ... », art. cit., p. 994.

${ }^{5}$ J.-A. BRUTAILS, La coutume d'Andorre, Leroux, Paris, 1904.

${ }^{6}$ J.-A. BRUTAILS, «Etude sur l'article 72 des Usages de Barcelone connu sous le nom de loi stratae », Revue d'Histoire du Droit, 1888, p. 59-79; et sa critique serrée : L. ASSIERANDRIEU, Le peuple et la loi. Anthropologie historique des droits paysans en Catalogne française, Paris, 1987.
} 
n'est ni française, ni anti-française, ni même étrangère ${ }^{7}$. Il convoque alors le droit et l'histoire («œuvre pratique et utile ») parce que, pour lui, les faits se trompent ou veulent tromper ; cette ligne de séparation doit exister.

La méthode qu'il emploie est à ce point limpide qu'elle fait apparaître une certaine instabilité des classifications (historiques, juridiques, géographiques, politiques et sociales) comme le fondement caché du régime andorran ; elle suggère ainsi les hypothèses que nous voudrions mettre à l'épreuve ici. Pour fonctionner, le discours de Brutails nécessite l'opposition exclusive de deux Etats-nations. Ce schéma n'a eu aucun succès en Andorre, et cela peut s'expliquer de diverses façons. Mais ce qui retiendra notre attention, c'est la part de ce revers qui était inscrite dans les structures profondes de la société andorrane. Plutôt que de forcer cette «perpétuelle équivoque »dont Brutails savait pertinemment qu'elle était constitutive des équilibres du pays, nous voudrions observer ces faits qui diluent la rupture fondatrice de la dialectique frontalière.

En présentant les éléments du débat auquel Brutails participait avec tant d'allant, nous souhaitons d'abord exposer quelques traits saillants de l'histoire andorrane, puis isoler les représentations qui sous-tendaient la controverse. Nous voudrions, ensuite, montrer comment ces figures furent manipulées dès le XIV siècle. Il sera temps alors de découvrir les scènes essentielles où se jouait l'ordre social d'Andorre et leur place dans le rejet d'une certaine forme de frontière.

\section{1/ La frontière nécessaire}

Grande oubliée des traités internationaux qui firent la frontière francoespagnole ${ }^{8}$, Andorre fut à la fin du XIX ${ }^{\mathrm{e}}$ siècle, l'objet de polémiques connues sous l'appellation de Question d'Andorre'. La querelle qui opposa Brutails et Baudon de Mony, deux anciens élèves de l'Ecole des Chartes qui venaient d'achever leur thèse ${ }^{10}$, en fut un paroxysme. Voyons pourquoi.

Le statut contemporain d'Andorre est le fruit d'un contrat de paréage signé en 1278 et complété en 1288. L'évêque d'Urgell et le comte de Foix s'y partageaient tous les droits qu'un seigneur pouvait, dans ces années, posséder sur ce pays. Les évêques d'Urgell se sont succédé jusqu'à nos jours, cependant que la France succédait aux comtes de Foix, après les rois de Navarre puis les rois de France. Toutes les difficultés du régime andorran résultaient de là. Comment mettre en œuvre ce texte du XIII ${ }^{\mathrm{e}}$ siècle dans des contextes profondément modifiés ? On ne peut que rappeler les mots de Paul Ourliac:

\footnotetext{
${ }^{7}$ P. OURLIAC, «La réforme des institutions andorranes », Publications de l'Institut d'Etudes Politiques de Toulouse, $\mathrm{n}^{\circ}$ 5, 1970, p. 119-151, repris dans P. OURLIAC, Etudes de droit et d'histoire, p. 308 et p. 309 note 50.

${ }^{8}$ P. SAHLINS, Boundaries. The Making of France an Spain in the Pyrenees, Berkeley, 1989.

${ }^{9}$ E. LOPEZ et J. PERUGA, Diplomatari de la vall d'Andorra. segle XIX, Andorra, 1994, p. 5761.

${ }^{10}$ C. BAUDON DE MONY, Les relations politiques des comtes de Foix avec la Catalogne jusqu'au début du XIV siècle, Paris, 1896 ; J.-A. BRUTAILS, Etude sur la condition des populations rurales du Roussillon au Moyen Age, Paris, 1891.
} 
«Il y a longtemps que les publicistes cherchent à ramener cette constitution aux catégories actuelles du droit international, mais ils n'y sont pas parvenu et, d'ailleurs, ils ne pouvaient le faire. Un pariage, comme son nom l'indique, est un partage, fait sur une base d'égalité, des possessions et des droits que deux seigneurs possèdent sur une même terre; par ses clauses et par son esprit, il appartient au droit féodal et ne peut se comprendre que par celui-ci ${ }^{11}$.

Malgré qu'en eût Brutails, Andorre aurait donc déjoué la partition du droit et de l'histoire que lui assignait son futur juge. Ce ne sont pas les preuves ${ }^{12}$ qui firent l'Andorre, mais le constat d'une coutume qui, nous citons à nouveau Paul Ourliac, « a modifié le traité de 1278 autant qu'elle l'a confirmé ». Sous cet angle, «la co-souveraineté est l'expression moderne du partage de la justice $»^{13}$, laquelle était répartie dès 1278 .

Ainsi se résume la Question d'Andorre : est-il possible que la souveraineté des Vallées soit revendiquée d'après le seul texte des paréages ? Avec le maître juriste d'aujourd'hui,l'on doit convenir que non. Au contraire, pour nos deux chartistes d'hier, la réponse était oui mais en regard du contexte. En effet, avec une hantise paradoxale de l'anachronisme, ils ont voulu lire dans le passé la solution des problèmes de leur époque. Comment opéraient-ils ?

\section{Une manipulation du temps : la Question d'Andorre}

L'un et l'autre considéraient d'abord que l'acte de 1278 était « la base principale du droit public en Andorre ${ }^{14}$. En historiens, ils pensaient que ce texte avait un sens très précis, unique et définitif. Pour découvrir ce sens, ou pour établir les liens que nouait cet acte, il fallait le replacer dans son contexte. Mais que se passait-il si le texte avait été interprété au delà de ce qu'entendaient faire ses rédacteurs ? Baudon de Mony affirmait ne pas s'en préoccuper, et demeurer «dans les régions calmes et sereines de l'érudition»" Brutails n'en croyait rien $^{16}$ : si l'on montrait que le texte voulait dire autre chose, des conclusions en seraient tirées (à son avis, J. D Trias ${ }^{17}$ l'avait fait pour Baudon de Mony), et l'histoire devrait être réformée. Suivons maintenant leurs arguments.

\footnotetext{
${ }^{11}$ P. OURLIAC, « La réforme ... », (art. cit.), p. 292.

${ }^{12}$ Le mot de preuve doit ici être entendu avec le sens que lui donnait précisément la diplomatique.

13 op. cit., p. 295.

${ }^{14}$ J-A. BRUTAILS, « ... Réponse à M. Baudon de Mony », (art. cit.), p. 579.

${ }^{15}$ C. BAUDON DE MONY, «La vallée d'Andorre et les évêques d'Urgell au Moyen Age », Revue des Pyrénées, 1892, p. 566.

${ }^{16}$ Il faut avouer que la position de C. Baudon de Mony manquait de clarté. Dans son premier article, celui qui devait déclencher la riposte de Brutails, il note que le débat a une certaine actualité, et pense que l'on peut tirer quelques conséquences de ses découvertes (C. BAUDON DE MONY, «Origines historiques de la question d'Andorre », Bibliothèque de l'Ecole des Chartes, 1885, p. 95-107).

${ }^{17}$ J. D. TRIAS, Constitución política ..., op. cit.
} 
Baudon de Mony apportait aux historiens un certain nombre d'éléments qui n'ont pas été démentis par les médiévistes d'aujourd'hui ${ }^{18}$. Il montrait que les paréages sont la conclusion d'un long conflit qui opposa les évêques d'Urgell et leurs feudataires, notamment (et non exclusivement) à propos d'Andorre. Dès 1133, la Mitre urgélitaine avait en effet hérité de tous les droits que les comtes d'Urgell possédaient sur le pays. Dans ces années de dislocation de la puissance publique, cela signifie que les prélats devenaient les seuls maîtres des Vallées. Ils inféodèrent aux seigneurs de Caboet une part des revenus et des droits qu'ils y possédaient, et c'est ce fief qui par succession devait échoir au vicomtes de Castelbon, puis aux comtes de Foix. A l'image de leurs prédécesseurs, ces derniers entrèrent en guerre ouverte avec la cathédrale. Il en résulta les actes de 1278 et 1288 qui partageaient la seigneurie d'Andorre et imposaient aux comtes de faire hommage à l'évêque. Les comtes étaient donc feudataires à l'origine, et les paréages répartissaient, sur une base d'égalité toute nouvelle, les droits de chacun. L'hommage exigé de Foix était comme un rappel de leur ancienne sujétion.

Pourquoi Brutails ne put-il accepter cette thèse frappée au coin de la meilleure érudition ? C'est qu'il fallait pour cela admettre que les droits de la France procédaient de l'émancipation d'un vassal; il y voyait une atteinte à la souveraineté française, cette "pureté originelle du droit sur lequel s'appuie la République française ${ }^{19}$. L'exclusive de son raisonnement le conduisait à nier aux évêques toute souveraineté ; qualité immuable qui ne se perd ni ne s'invente, elle pouvait tout au plus avoir été cédée, mais avec des titres, avec des preuves.

Le principal de sa réponse s'organisait en deux temps. Il objectait d'abord que si les paréages distribuaient «diverses attributions [...] de nos jours, caractéristiques de la souveraineté », elles ne l'étaient pas au XIII ${ }^{\mathrm{e}}$ siècle ${ }^{20}$. Est-ce à dire que, dans son esprit, la souveraineté devenait soudain un objet d'histoire ? Il n'en est rien. Brutails ne considérait ici que ses attributions : le merum imperium, «cette juridiction qui, après la royauté, était la plus haute expression de la puissance publique dans le monde féodal $»^{21}$. La souveraineté essentielle et inaltérable était donc logée pour Brutails dans cette « puissance publique » qui dominait le monde féodal : la royauté. On ne peut qu'admirer le tour de force qu'il accomplit ainsi. La souveraineté a une histoire, celle de ses attributions, mais la souveraineté en elle-même est au delà de l'histoire. Ce qui fait la souveraineté d'aujourd'hui n'est pas ce qui l'a produite. La souveraineté est une transcendance.

Cette métaphysique n'était pas gratuite. En opérant de la sorte, Brutails dégageait la souveraineté des relations féodales. Toutes les pièces apportées par Baudon de Mony sur les origines de la co-seigneurie d'Andorre étaient donc

\footnotetext{
${ }^{18}$ J. GUILLAMET, Aproximació a la historia social, economica i politica d'Andorra (segles IXXIII), Andorra, 1991.

${ }^{19}$ C'est Brutails lui-même qui souligne, dans cette expression qu'il a traduite de J. D. Trias. Même si ces mots sont appliqués au contexte de la rédaction des paréages et non à la suzeraineté de l'évêque d'Urgell, la réaction de Brutails est révélatrice (J.-A. BRUTAILS, « Etude critique ... », art. cit., p. 985).

${ }^{20}$ J.-A. BRUTAILS, « Etude critique... », art. cit., p. 968.

${ }^{21}$ Ibidem, p. 988.
} 
déclarées «sans conséquences ». La souveraineté ne pouvait être que dans des mains royales, à moins qu'un acte témoignât de sa cession ${ }^{22}$.

Cela rend étrange la seconde partie de sa réplique. Pourquoi s'efforça-t-il de montrer que tous les droits des comtes de Foix ne dérivaient pas du fief des Castelbon, alors que, selon lui, la question de la souveraineté sortait vierge de ces péripéties ? C'est que, s'il pouvait arguer de l'absence de titre souverain des évêques, les rois de France, en Andorre, n'en possédaient pas plus. Les seuls droits attestés de la France provenaient de Foix. Si ces derniers découlaient d'un fief, il ne pouvait y avoir de présomption de souveraineté qu'en faveur de la Mitre $^{23}$. Brutails était ainsi contraint de ménager une brèche dans l'histoire, une ouverture qui laissât la souveraineté d'Andorre accessible à la France.

Pour comprendre ses choix, il faut analyser le résultat des manipulations qui ont fait la question d'Andorre. La première est la réification du droit, sa réduction à une suite de faits juridiques, de droits. Ceux-ci, découpés avec soin, créent une matière définie, et la tâche de l'historien se limite à dire qui détient lesquels, selon le moment. La deuxième opération consiste à immobiliser six siècles d'histoire. Comme base actuelle du droit public, le texte de 1278 doit répartir ces droits dans l'Andorre de 1890, malgré six cents ans d'évolutions sociales et de gloses successives. Puisque ne s'y trouve pas la nomenclature actuelle du droit, il faut procéder à une troisième étape : assigner à des formulations du Moyen Age la représentation de droits contemporains. Ces trois mouvements, cela se perçoit aisément, ont pour effet de ravaler l'histoire et le droit au rang de répertoires figés d'où l'on extrait l'argument idoine; c'est dire qu'ils rendent indisponibles l'histoire et le droit comme herméneutique du changement social ou de l'écart entre le texte et les faits.

Brutails, au bout de l'emballement de ces logiques, se trouve face à un gouffre : il a placé la souveraineté hors du champ historique, en déclarant qu'aucune preuve n'était décisive, et hors du droit positif, en lui donnant un double statut, celui d'abstraction ( «l'expression la plus haute de la puissance publique ») liée à un ensemble de droits concrets, mais indéterminés et flottants. Pour sortir de cette impasse, il introduit une nouvelle variable : l'espace.

\section{La souveraineté, un espace en question}

On sait aujourd'hui que souveraineté et suzeraineté découlent d'une même notion de supériorité. Appliquée aux relations féodales, la suzeraineté désignait la suprématie de celui qui se trouvait au sommet d'une pyramide de liens personnels, dits vassaliques. Elle permit, en France, l'affirmation du pouvoir royal

\footnotetext{
${ }^{22}$ Par défaut, et Brutails prend soin de formuler cela comme une galéjade hors de propos, « pourquoi ne pas remonter à Charles le Chauve et à Louis le Pieux » qui, comme chacun sait, sont d'anciens rois de France et, accessoirement, les derniers rois connus qui furent maîtres exclusifs d'Andorre ? Baudon de Mony lui rappela l'existence du traité de Corbeil («La vallée d'Andorre ... », (art. cit.), p. 568).

${ }^{23}$ Comme les droits de l'évêque étaient issus d'une donation du comte d'Urgell, il fallait justifier des droits souverains de la France sur ce comté catalan ; c'était une gageure (voir notamment la réplique sur ce point dans C. BAUDON DE MONY, «La vallée d'Andorre ... », (art. cit.), p. 568).
} 
entre le milieu du $\mathrm{XII}^{\mathrm{e}}$ siècle et celui du XIII ${ }^{\mathrm{e}}$. Elle devint souveraineté dès lors que cette hiérarchie était englobée dans une autorité qui ne se contentait plus de dévaler les échelons d'une fidélité en cascade, mais pesait sur tous les hommes d'un territoire. Cela s'accomplit à partir des années 1260 en France $^{24}$, mais bien avant en Catalogne ${ }^{25}$. Retenons l'essentiel : les deux notions sont l'œuvre juridique d'un pouvoir en reconstruction matérielle. La première autorisait une pyramide des fiefs au sommet de laquelle se trouvait le suzerain, la seconde unifiait l'espace sous l'égide d'un souverain.

Pour Brutails, en revanche, la souveraineté est une transcendance, non pas l'outil d'un pouvoir en construction, mais sa légitimité. Ne pouvant argumenter sur le contenu de cette suprématie, il est aussi mis en échec sur l'origine de la seule autorité attestée, le lien vassalique. Pour y remédier, il en est réduit à discuter du ressort de cette supériorité. Aussi, feint-il de croire deux choses, d'une part, que cette prééminence ne s'appuyait que sur une partie du sol andorran, d'autre part, que la souveraineté d'Andorre, par définition, ne pouvait concerner que l'ensemble du territoire des Vallées.

Par delà, rien ne sert de suivre pas à pas les méandres de sa pensée. Tout se résume à cet énoncé : les comtes de Foix ont hérité du fief épiscopal, c'est-àdire d'un «fief taillé dans les Vallées. Or l'étendue d'un fief pouvait varier indéfiniment $\gg^{26}$. Il en conclut implicitement qu'Andorre est faite de deux pièces : d'une part, le fief de la Mitre, fraction de l'espace des Vallées qui à ce titre ne peut prétendre à la souveraineté, et, d'autre part, tout le reste du pays. Au prix des pires invraisemblances, il considère qu'Andorre est traversée par une ligne qui sépare le fief épiscopal d'une aire où peuvent agir les comtes de Foix, et où pourrait être logée la souveraineté. Cette ligne inventée devient alors le front d'une guerre séculaire qui limite la portée des textes juridiques à celle de communiqués d'états-majors sur l'avancée des belligérants. ${ }^{27}$.

Cette démarcation est une projection assez fruste de la frontière francoespagnole ${ }^{28}$. Pour Brutails, en la repoussant jusqu'aux confins d'Andorre, les comtes de Foix ont imposé la souveraineté française. Il écrase alors l'histoire pour la plier à cette polarisation : il produit mille arguties ${ }^{29}$ jusqu'à relever que les comtes de Foix et la France ont, depuis les paréages, exercé des droits souverains en Andorre. Ce dernier stratagème nous montre de quelle façon il aplatit

${ }^{24}$ J.-F. LEMARIGNIER, La France médiévale, institutions et société, Armand Colin, Paris, 1970, p. 255-263.

${ }_{25}$ T. N. BISSON, «The Problem of Feudal Monarchy : Aragon, Catalonia and France », Speculum, vol. 53, $\mathrm{n}^{\circ}$ 3, 1978, p. 460-478; «The Organized Peace in Southern France and Catalonia, ca 1140-ca 1233 », The American Historical Review, T. 82, 1977, p. 290-311.

${ }^{26}$ J-A. BRUTAILS, « Etude critique ... », art. cit., p. 981.

${ }^{27}$ Lui objecte-t-on tel acte qui montre que les évêques possédaient certains droits sur toute l'Andorre, c'est qu'ils avaient poussé un avantage. Lui oppose-t-on qu'ils ont en 1231 reçu un hommage des représentants de tous les Andorrans, c'est que la cathédrale avaient dépouillé les comtes de leur fief. Par ailleurs, il produit des actes symétriques qu'il interprète de façon assez grotesque comme la preuve de conquêtes fuxéennes (Ibidem, p. 981-885).

${ }^{28}$ C'est-à-dire une aire au statut flou, sise entre la France et l'Espagne, Etats souverains, et une aire dont la domination est disputée par la France (Etat souverain) et l'évêque d'Urgell.

${ }^{29}$ Charles le Chauve n'a pas formellement cédé la souveraineté d'Andorre ; les rois de France aurait pu rappeler leur souveraineté lors des paréages s'ils ne s'étaient trouvés trop loin ; l'évêque d'Urgell n'a aucun titre faisant l'inventaire complet de ses droits ; le comte de Foix a conquis Andorre pied à pied (Ibidem, p. 981-985). 
également le droit. Brutalement, il voit là une preuve de la souveraineté française ; ce serait sans nul doute une erreur, un expédient, une usurpation de la part des évêques d'Urgell ${ }^{30}$. Rien n'existe plus hors la frontière.

En somme, et malgré des conclusions symétriquement opposées, Brutails et Trias, s'accordent sur l'existence plus que millénaire d'une frontière, et tous deux en appellent, pour la rétablir, à une lecture « du double point de vue de l'histoire et du droit». Or, pour parvenir à cette réduction spatiale, alors que Baudon de Mony a choisi de jeter l'éponge, ils maltraitent férocement ces deux disciplines. Pourquoi, par conséquent, s'imposent-ils ce détour hasardeux ? Pourquoi sacralisent-ils cette frontière qu'ils échouent à démontrer ?

\section{Espaces et identifications d'un ordre social}

Pour J.D. Trias, il faut empêcher « la création d'un autre Gibraltar, dans les entrailles des Pyrénées », pour conserver "l'idée espagnole dans les Vallées $»^{31}$. Le sol est porteur d'une identité nationale; il est le socle naturel sur lequel doit s'épanouir le génie d'un peuple, et que devraient ratifier le droit et l'histoire. Or il en va de même pour Brutails : "Si on niait la nationalité française des villes et des provinces au sujet desquelles des actes analogues [aux paréages] ont été signés sans participation de nos rois, il ne resterait peut-être plus au gouvernement de la République un pouce de terre pour y planter son drapeau ${ }^{32}$. C'est signifier que la nationalité, qualité intrinsèque de chaque arpent, unit les rois et le gouvernement de la République ; le drapeau, symbole de souveraineté, peut changer de mains, mais le sol où on le fiche a une identité qui doit forcer son destin.

Il ne s'agit pas, pour nous, de traquer nationalismes et positivismes de ces savants, mais de rendre visible ce qui les déroutait. Quelle est la nationalité d'Andorre ? Au regard du droit international, il est unanimement admis qu'une nationalité ne peut être conférée que par un Etat souverain. C'est bien sûr ce qui sous-tendait les recherches de Brutails et Trias, et les enfermait dans une logique circulaire $^{33}$. De façon triviale, l'histoire culturelle, économique et sociale du pays montre qu'il est catalan et pyrénéen, ce qui n'aide guère à décider en faveur de l'Espagne ou de la France. Pour en statuer, ils devaient donc s'en remettre à une escapade périlleuse dans le droit et l'histoire institutionnelle d'Andorre.

De là résulte leur besoin d'une antique délimitation nationale. Déplacée d'un côté ou de l'autre d'Andorre, elle est chargée de prouver l'adéquation qu'ils supposent entre nation et souveraineté, malgré le silence des textes. Mais elle permet surtout de nier l'évidence qui rend leur débat parfaitement creux : à l'orée

\footnotetext{
${ }^{30}$ Quant à l'hommage que devait les comtes de Foix, il n'est plus à l'origine de quoi que ce soit, c'est une affaire d'ordre privé ; au pire, on invoquerait la prescription, le droit international, ou le sens du ridicule.

${ }^{31}$ J. D. TRIAS, Constitución política ..., op. cit., p. 43; cité et traduit dans J.-A. BRUTAILS, «Etude critique ... », art. cit., p. 962.

${ }^{32}$ J.-A. BRUTAILS, « Etude critique ... », art. cit., p. 987 ; c'est nous qui soulignons.

${ }^{33}$ Comment prouver la souveraineté par la nationalité si la seconde découle de la première ? Sur ces problèmes : P. OURLIAC, «Existe-t-il une nationalité andorrane? », Mélanges J. Maury, 1959, p. 403-415.
} 
du $\mathrm{XX}^{\mathrm{e}}$ siècle, Andorre existe juridiquement en marge des nations ; Andorre s'est développée sous la double souveraineté des évêques d'Urgell et des comtes de Foix, puis de leurs successeurs ; Andorre est un monstre juridique.

«Peut-on, en effet, rien imaginer de plus absurde qu'un pays géré par deux souverains, un évêque catholique et la France révolutionnaire, également souverains et investis d'attributions égales ? Le pouvoir épiscopal monarchique et le gouvernement français républicain ? L'évêque autorité nationale et la France autorité étrangère ? Celui-là dictant les lois dans le sentiment de l'unité du catholicisme et celle-ci d'après les idées rationalistes de la Convention ? le premier dans la tradition catalane et la seconde s'inspirant du césarisme du code Napoléon?»

Ces mots de Trias sont, pour Brutails qui les traduit, les « lois imprescriptibles du bon sens », celles que l'on « invoque contre la dualité de la puissance suprême ». Certes, l'hydre à deux têtes est là pour servir de repoussoir, mais comment fonctionne cet épouvantail ? La souveraineté est ici comprise dans son acception moderne de pouvoir irrésistible qui autorise, construit et impose la loi ; mais un pouvoir qui ne se concrétise que dans l'action d'un Etat. Or s'il y a une souveraineté de trop en Andorre, il y manque un Etat. C'est pourquoi la menace opère en réalité sur deux registres.

1/ Elle pose d'abord une alternative rejetée en bloc. Si les deux co-princes convenaient qu'ils n'ont pas d'Etat en Andorre, leur souveraineté se révélerait chimère sans efficacité. Ce serait signifier qu'il existe quelque part en Europe une société où les lois n'ont pas de sanction juridique, où donc le droit existe sans raison. Si chacun des co-princes construisait un Etat, le pouvoir d'imposer un ordre plutôt qu'un autre ne découlerait d'aucune majesté mais des capacités matérielles de contrainte dont chacun disposerait ; le droit n'aurait donc qu'une place subsidiaire. Dans la culture occidentale, cette société, qui ne serait pas fondée dans le droit, est ce qu'on peut «imaginer de plus absurde », ce qui défie les «lois imprescriptibles du bon sens ».

2/ Cependant, le péril de déraison survit en deçà de cette appréhension. L'essentiel de la vindicte de Trias se porte sur un plan subséquent. A supposer pour sauver le droit - qu'un Etat et un seul existe, soit les souverains accordent leurs volontés et dotent l'Etat d'une législation unique, soit ils supposent deux lois contradictoires, à charge pour l'Etat d'en extraire une action commune. Nos deux auteurs fulminent. Si l'on peut forger une unité à partir de deux volontés différentes, si l'on peut trouver une part commune à deux lois opposées, c'est que leurs discriminations ne sont pas indépassables ; c'est qu'il y a chez l'autre une part de nous-mêmes et qu'un seul Etat pourrait absorber toute la surface du globe. Mis en demeure d'accepter, au nom du droit, cette dialectique intégrative, Trias ne raisonne plus, mais recourt comme Brutails à l'opposition la plus insoluble qu'il puisse imaginer : le national et l'étranger ${ }^{34}$.

\footnotetext{
${ }^{34}$ Pour nos deux savants, c'est le fait national qui fonde la souveraineté de leurs propres sociétés, et la souveraineté qui permet un ordre social. C'est pourquoi l'on peut considérer que les litanies d'oppositions que formule Trias (l'unité du catholicisme et le rationalisme de la convention, la tradition catalane et le code Napoléon, la monarchie et la République) ne sont là que pour affermir l'impression de césure infranchissable.
} 
Stupéfait par le cas andorran, il nous livre en creux une leçon frappante sur la place de la souveraineté dans le droit. Pour prendre en charge l'ordre social (les lois), la souveraineté doit conformer la contrainte (de l'Etat) à la raison (du droit), et l'acte premier de cette allégeance est de garantir que ce qui est soumis à la contrainte est raisonnablement distinct de ce qui ne l'est pas ; la souveraineté doit identifier la société qu'elle ordonne.

Plutôt que d'oser l'abord direct et vertigineux de cette caractérisation, on peut user des garde-fous de l'historien et comparer ces conclusions au trajet de la souveraineté à travers le temps. Artifice rhétorique d'une puissance sociale et matérielle en construction (en France, les rois à partir du XIII ${ }^{\mathrm{e}}$ siècle), la souveraineté a suivi puis accompagné la revendication d'une emprise territoriale, et pris fin lorsque une énergie équivalente l'a bornée. Aux yeux de l'histoire comme science sociale, la souveraineté a donc la même fonction mais un tout autre visage; en modifiant son libellé selon le temps, elle a donné pour raisonnable la contrainte que des pouvoirs successifs (des Etats putatifs, mais avant tout des puissances matérielles) ont exercé sur des sociétés territorialement déterminées ${ }^{35}$.

Le vertige juridique utilisé par Brutails et Trias comme repoussoir est donc le fruit du gouffre qu'Andorre fait apparaître entre le rôle de la souveraineté dans l'architecture du droit et ce qui fit son efficacité historique, à savoir les strates matérielles et idéologiques des Etats occidentaux. Ici explose le montage des Etats-nations, et l'absence de frontière n'est absurde qu'à l'échelle de rationalité de ces derniers. Aussi, la fiction de frontière mise en place par Brutails et Trias échouait parce qu'elle contredisait trop visiblement la réalité andorrane, parce qu'elle n'était pas relayée par la puissance réelle d'un Etat. ${ }^{36}$.

Avant de découvrir cette réalité, nous voudrions souligner deux choses. Il faut noter d'abord que, si de nombreux juristes ont achoppé sur ce cas, d'autres ont su combler cette béance entre la vocation de la souveraineté dans le droit et le dossier andorran ${ }^{37}$. Ainsi, Paul Ourliac, en manipulant la coutume et les catégories juridiques sans figer ni l'histoire ni le droit, parvenait à une mise en scène qui consacrait une nation andorrane, réconciliait la Convention et la théorie canonique, l'originalité andorrane et l'apparence immuable du droit. ${ }^{38}$. L'histoire

\footnotetext{
${ }^{35}$ Ce constat permet de court-circuiter deux douloureuses questions; la place sociale du droit et la propension de l'Etat territorial à assumer tous les pans de l'ordre social.

${ }^{36}$ A leur décharge, on doit souligner qu'aux environs de 1900 le concept de souveraineté partagée - et inventée du passée - était une arme efficace pour les Etats-nations qui voulaient déplacer leurs frontières (D. NORDMAN, « Des limites d'Etat aux frontières nationales », dans P. NORA, Les lieux de mémoire. II. La Nation, Gallimard, Paris, 1986, t. 2, p. 49).

${ }^{37}$ Les études de droit sur Andorre sont pléthore. Pour un premier accès : J. BELINGUIER, La condition juridique des vallées d'Andorre, Paris, 1970.

${ }^{38} \mathrm{Il}$ faut suivre pas à pas son raisonnement pour en saisir l'ingéniosité. Après avoir rappelé que les paréages sont inintelligibles en droit international, il mentionne la présence d'une forme de self-government qui, depuis aussi loin que les paréages, régit la vie courante des Andorrans. Ce Conseil des Vallées émane d'une communauté andorrane indéniable qui, comme toute communauté, développe un droit propre. Il existe donc un peuple, un territoire et un quasi-Etat, seule la souveraineté fait problème. Mais, nous dit-il, la coutume a modifié le traité de 1278 ; "plus même qu'un principe constitutionnel, le pariage est devenu un mythe : mythe de durée et mythe d'équilibre ». Il n'est donc plus question de savoir ce que disait le texte, mais si le mythe doit survivre. Les Andorrans ont montré qu'ils le souhaitaient vivement. Paul Ourliac en concluait que les co-princes ne peuvent modifier la constitution d'Andorre parce que « la tradition
} 
ultérieure lui a donné raison. On doit, nonobstant, retenir la leçon des déboires de Brutails et Trias. Même si la souveraineté des Etats-nations est un produit historique, elle occupe une place nécessaire en ce qu'elle donne une cohérence juridique à la contrainte qui réalise l'ordre social ${ }^{39}$. A défaut d'autres spécifications, les frontières transcendent les formes successives de l'Etat en circonscrivant des populations unies par une identification rétrospective. S'est-on rendu compte que seule l'opposition du national et de l'étranger permet d'accepter les principes d'ordre irréconciliables énoncés par Trias, et de faire oublier tout ce qu'il y a d'incongruité à ranger sous une même rubrique, comme il le fait, l'évêque d'Urgell, la monarchie, l'unité du catholicisme, la tradition catalane et la nation espagnole ?

\section{2/ Une terre distincte et séparée, mais pas étrangère}

Quelques documents du XIV siècle témoignent d'équivalentes tentatives d'intégration de l'espace andorran. Ils jettent une lumière crue sur les mécanismes à l'œuvre mais, surtout, révèlent brutalement le rôle de la société andorrane dans l'élaboration d'une frontière diffractée.

Des paréages à Gaston Fébus, les comtes de Foix furent bien plus des princes des Pyrénées que ces représentants du camp français que Brutails imaginait parfois. Possessionnés en Gascogne, en Catalogne et pays de Foix, ils devaient s'arranger d'une triple vassalité, souvent inextricable, envers les rois de France, d'Angleterre et d'Aragon. Profitant d'un contexte favorable, Gaston III affirma son indépendance en déclarant le 26 septembre 1347 qu'il se trouvait en Béarn, «terre qu'il tient de Dieu et de nul homme au monde, d'où ne découle pour lui aucune obligation si ce n'est de faire ce que bon lui semble $»^{40}$. Il proclamait ainsi sa souveraineté sur le Béarn, en niant qu'il fût tenu en fief. Or, à la même époque, il faisait réaliser une enquête auprès des Andorrans visant à démontrer qu'elle était terre distincte et séparée de toutes les contrées avoisinantes $^{41}$. Le parallélisme est évident. Les treize points de cette information, déclarent que nul autre que les co-seigneurs ne dispose de droits juridictionnels et

démocratique est trop vive et trop ancienne dans le pays pour ne pas imposer une intervention directe du peuple. Le principe, affirmé par la Convention, le 21 septembre 1792, est devenu l'un des axiomes du droit constitutionnel : "il ne peut y avoir de constitution que lorsqu'elle est acceptée par le peuple" ». Cela n'est même pas une nouveauté mais comme la prolongation de « la vieille théorie canonique de l'approbatio legis : c'est le consensus du peuple andorran qui crée la valeur constitutionnelle du pariage ». Plus encore, "les co-princes ne pourraient ni supprimer le Conseil, ni le suffrage des habitants car ce serait aller contre le principe de la souveraineté populaire ».

On ne peut qu'admirer la virtuosité de l'enchaînement et en relever quelques résultats. La co-souveraineté est un produit de la coutume, un mythe qui relève de la souveraineté des Andorrans, qui garantit leur droit, leur Conseil des Vallées, lequel d'ailleurs gère le principal des affaires d'Andorre à la manière d'un Etat. Quant à la charge d'identification de la souveraineté, elle s'accomplit dans un «égal loyalisme [des Andorrans] pour leurs deux co-princes », dans cette nationalité qui est une « citoyenneté » et « une mentalité ».

${ }^{39}$ L. ASSIER-ANDRIEU, Le droit dans les sociétés humaines, Paris, 1996, p. 44-45.

${ }^{40} \mathrm{P}$. TUCOO-CHALA, La vicomté de Béarn et le problème de sa souveraineté des origines à 1620, Bordeaux, 1961.

${ }^{41}$ I. BAIGES et M. FAGES, Diplomatari de la Vall d'Andorra, Andorra, 1993, p. 98-110. 
politiques en Andorre, et qu'elle n'est rattachée à aucun autre ressort ou district. Il s'agit de montrer qu'Andorre est un franc-alleu, une terre d'aucune mouvance, d'aucune autre suzeraineté, ni souveraineté.

Que la vallée d'Andorre soit ..., et elle aura toujours été...

De ce document, deux éléments méritent une attention particulière. On doit remarquer d'abord l'habileté du questionnaire et le parfait entendement de ses enjeux par les Andorrans. En prétendant qu'Andorre est terre différente des pays voisins, le formulaire mentionne la Cerdagne, l'évêché d'Urgell, le haut Urgell et la vicomté de Castelbon. En mêlant la Cerdagne (dont Andorre n'a historiquement jamais fait partie) à l'évêché d'Urgell (dont les Vallées ne sont dissociées que par les paréages) et à la vicomté de Castelbon (à l'origine des droits fuxéens et placée sous la souveraineté des comtes de Barcelone), la nature de la distinction est effacée. En outre, sont passés sous silence d'autres confronts comme les comtés de Pallars et surtout de Foix, mais aussi l'appartenance ancestrale des Vallées au comté d'Urgell. Parce qu'Andorre était sise à l'intersection de tant de territoires, il était possible de faire comme si elle n'appartenait à aucun. En déclarant vaguement qu'elle était « distincte et séparée de toutes les terres et lieux qui la cernaient », on affirmait l'évidence (Andorre n'est pas la vallée de Sant Joan) et le plus problématique, placé dans la bouche d'un Andorran : «le roi de France et le roi d'Aragon n'ont aucun droit sur cette vallée ».

Seconde ligne de force du document, le procédé de l'enquête n'est pas innocent. Il est demandé aux habitants de témoigner que cette distinction et cette soumission à deux co-seigneurs sont immémoriales, c'est à dire très précisément qu'elles ont toujours été ainsi, de telle sorte qu'aucune mémoire d'homme ne peut s'inscrire en faux. Le plus vieux des témoins déclare avoir une mémoire remontant à soixante ans en arrière, les paréages ont à cet époque là soixante-dix ans. Rarement, sans doute, la coutume, l'immémorial et l'enquête furent instrumentalisés de façon aussi patente. Le génie de ce questionnaire est de présenter une situation dont chacun sait qu'elle date des paréages comme une vérité de toujours (quod vallis Andorre sit et semper fuerit... ${ }^{42}$ ). Enoncée sous cette forme, la souveraineté des deux co-princes ne relève plus d'aucune transmission, d'aucune histoire, elle est le produit de la terre.

L'emboîtement de ces deux opérations fait leur efficacité. La solide personnalité historique d'Andorre est renforcée par la pérennisation d'un pouvoir politique indépendant. Dans le même temps, ce dernier s'appuie sur l'ancienneté et les particularités du territoire andorran, pour s'affirmer face aux rois de France et d'Aragon. Enfin, la méthode de l'enquête coutumière a pour effet de lier dans l'immémorial le pays et ses co-princes, d'attacher l'un aux autres de manière exclusive, c'est-à-dire en évitant toute référence gênante. C'est l'aire coutumière, qui construit le ressort, et fait apparaître la souveraineté, mais l'astuce du questionnaire est de présenter les droits historiques des co-princes comme les

\footnotetext{
${ }^{42}$ Dans son contexte, ce segment de phrase n'a pas la signification que nous lui prêtons ici. Cependant, isolé et détourné, il dit l'esprit du document dans son entier.
} 
seuls repères de l'identité andorrane ${ }^{43}$. Heureux de pouvoir affirmer leur particularité et de rejeter le poids d'autres seigneurs possibles, les Andorrans valident cette tautologie de la souveraineté. Ils savaient cependant leur terre construite sur bien d'autres oppositions, et savaient aussi les manier à l'occasion.

... selon sa fidélité et sa nature.

En 1369, les fermiers cerdans de certaines taxes douanières demandaient que soient imposées les marchandises entrant et sortant des Vallées, au double motif que les Andorrans étaient sujets du comte de Foix, lequel relevait du roi de France, et que, par ailleurs, ayant refusé de contribuer à l'effort de guerre levé par la Généralité de Catalogne pour le roi d'Aragon, ils devaient être considérés comme étrangers au Principat catalan. Les Andorrans disaient au contraire que leur vallée était sise dans les limites du royaume d'Aragon (qu'ils n'avaient donc pas à payer de droits de douane), mais aussi, par privilège, exempte de l'impôt. L'arbitre nommé par la chancellerie aragonaise ne pouvait guère accepter le raisonnement qui plaçait les Vallées dans le royaume de France et trancha donc en faveur des Andorrans ${ }^{44}$.

Devant l'insistance des fermiers, les Andorrans en appelèrent au comte de Foix qui, en 1379, obtint du roi d'Aragon la confirmation de ce jugement, pour les mêmes raisons, mais aussi parce qu'Andorre était au comte et que le roi n'entendait pas qu'il fût lésé ${ }^{45}$. Désir de souveraineté et droit féodal s'accordaient. Dans les années 1390, la Généralité de Catalogne prit le relais des fermiers de Puigcerdà contre l'équilibre qu'essayaient de préserver les rois aragonais. Un acte de 1392 résume parfaitement la situation ${ }^{46}$.

Les députés catalans expliquaient que les Andorrans avaient obtenu de la Généralité une dérogation pour les marchandises qui entraient ou sortaient entre «Gascogne » (on doit relever cette désignation qui permet de contourner la souveraineté française) et Andorre ou entre Catalogne et Andorre. En revanche, devaient être taxées les marchandises qui, par les Vallées, passaient de Gascogne en Catalogne et réciproquement. Mais les fermiers s'aperçurent que cela donnait lieu à une contrebande généralisée (qui concernait plus le Languedoc et le Toulousain que la Gascogne). Ils proposèrent donc aux Andorrans qu'une garde de douaniers fût établie entre Andorre et Foix ou que toutes leurs marchandises fussent taxées ; ils citaient à l'appui le cas des Aragonais et des Valenciens qui dépendaient aussi du royaume d'Aragon, mais payaient ces taxes pour n'être pas du ressort de la Généralité. Les Andorrans maintinrent qu'il étaient en Catalogne, mais $d u$ comte de Foix. Principes territoriaux et droit féodal étaient mis en opposition. Les Andorrans rejetaient l'alternative proposée ; ils avaient construit une double appartenance qui transformait le pays en sas douanier, et ne désiraient guère en perdre le bénéfice. Au demeurant, lorsque les rois d'Aragon essayèrent

\footnotetext{
${ }^{43}$ Les onze premières interrogations portent sur la répartition des droits seigneuriaux au seul bénéfice d'Urgell et Foix, les deux dernières sur la distinction et séparation d'Andorre des pays voisins, sans qu'aucun critère de différentiation ne soit proposé.

${ }^{44}$ I. BAIGES et M. FAGES, Diplomatari..., (op. cit.), p. 171-172.

${ }^{45}$ Ibidem, p. 181-183.

${ }^{46}$ Ibidem, p. 239-242.
} 
d'obtenir l'hommage des Andorrans, ils invoquèrent autant leur fidélité vassalique (le suzerain récupérait l'hommage dû au vassal félon) que leur naturalesa (l'attachement territorial à un souverain). La requête n'eut pas de suite $^{47}$.

Le contraste entre cette série de variations et la déclaration péremptoire de 1347 est éclatant. Andorre est séparée et distincte, mais on ne sait de quoi ni comment. Les entrecroisements de limites territoriales et de principes de supériorité tissent, autour d'Andorre, mille lambeaux de frontières. Mais ce XIV siècle des Vallées montre qu'il ne faut pas être dupe de l'expression juridique du discours andorran, des protestations d'appartenance à la Catalogne, par exemple. Qu'ils fussent culturellement et socialement catalans est un fait; qu'ils se déclarassent du Principat catalan ou des regalia d'Aragon est un artifice de droit. Les oppositions entre Urgell et Foix, France et Aragon, Catalogne et Gascogne, comme l'occultation du Languedoc, furent manœuvrées selon des stratégies mobiles et multiples qui trompèrent Brutails et Trias. Le statut des Vallées n'est pas le compromis fossilisé de deux puissances mais l'œuvre de plusieurs acteurs, et notamment des Andorrans (trop souvent supposés passifs) qui souhaitaient imposer une tout autre conception de la frontière, conception que ne défiguraient pas leurs motivations mercantiles du moment. Les Andorrans se voulaient distincts et séparés mais pas étrangers. Leurs frontières n'étaient le lieu d'aucune intégration mais les instruments d'un lien juridique revendiqué, celui qu'ils établissaient avec toutes les unités sociales environnantes (et de ce point de vue fidélité et naturalesa sont tout un). Pour comprendre ces frontières éclatées, il faut donc plonger vers les racines des communautés andorranes.

\section{3/ Un pays de frontaliers, un pays de voisins}

A partir du $\mathrm{XI}^{\mathrm{e}}$ siècle, de nombreux indices montrent la floraison en Andorre d'un type de société très répandu dans les hautes vallées pyrénéennes. Ces montagnards, qui vivaient d'une agriculture aussi cruciale que médiocre mais largement compensée par la richesse des ressources sylvo-pastorales, se mouvaient au sein de communautés fortement cimentées qui réglaient l'accès de chacun aux produits des terres collectives ${ }^{48}$. La communauté des voisins, la besiau au nord-ouest de la chaîne, était solidaire de ses membres en justice comme en guerre, en cas de délit commis par l'un d'eux comme de préjudice subi ${ }^{49}$. En outre, les hautes vallées se structuraient en communautés superposées ; les vallées étaient faites de sections qui comptaient à leur tour plusieurs sous-ensembles,

\footnotetext{
${ }^{47}$ Ibidem, p. 250-253.

${ }^{48}$ P. OURLIAC, «L'ancien droit des Pyrénées », Annals of the archives of Ferran Valls $i$ Taberner's library, 6, 1989, p.151-173.

${ }^{49}$ P. OURLIAC, «La justice et la paix dans les fors de Béarn »; «Les fors de Bigorre »; «Cautions et otages dans les fors de Béarn», Les Pays de Garonne vers l'an mil, Toulouse, 1993, p. 195-235.
} 
lesquels parfois groupaient eux-mêmes plusieurs hameaux ${ }^{50}$. Ici, les solidarités et les accès au territoire s'enchaînaient en cascade. Les conflits, fréquents et violents, étaient jugés par les communautés concernées, et s'il dégénéraient en guerre, le seigneur ne pouvait souvent faire mieux qu'imposer une paix, puis un arbitrage.

Si toutes ces hautes vallées admettaient un pouvoir supérieur, nombreuses étaient celles qui considéraient que son «autorité n'[était] pas imposée, mais acceptée $»^{51}$. En revanche, les princes s'appliquaient à opérer comme si cette légitimité procédait d'eux-mêmes, en légalisant ces situations originales qui niaient leur puissance. Il en résulte une opacité des textes, heureusement éclairés par certains documents.

\section{Le peuple et ses frontaliers}

En 1007, et pour la dernière fois d'après nos sources, le comte d'Urgell cédait certains droits sur Andorre en procédant à sa délimitation ${ }^{52}$. Ainsi, lorsqu'en 1133 il abandonna Andorre aux évêques urgélitains, il ne disposait déjà plus d'un ressort mais de droits que lui reconnaissaient un corps politique dont s'affirmait la mainmise sur le sol ${ }^{53}$. Cela devait durer. Ainsi, en 1332, un viguier des comtes de Foix octroyait aux Andorrans le privilège de pouvoir défendre les armes à la main leurs ademprivia et leurs montagnes contre tout agresseur, quels que fussent ses titres. Par ailleurs, un acte de 1295, montre que les Andorrans bornaient en toute indépendance leur vallée ${ }^{54}$. Même lors du renouvellement des paréage en 1288, le comte et l'évêque admettaient que l'emprise des ruines du vieux château d'Enclar resterait « perpétuellement de l'ademprivium des hommes d'Andorre, de la généralité et propriété de cette vallée ${ }^{55}$. La vallée était propriétaire de son sol (?), et à la disposition des Andorrans.

Si en apparence il ne s'agissait que de dominer l'usage de bois ou de pâturages, il ne faut pas oublier qu'autour de ces espaces s'organisaient toutes les sociétés pyrénéennes. En 1176, l'évêque d'Urgell obtenaient que les Andorrans portent devant lui les litiges qu'ils auraient avec leurs frontalers, « qui ont fait la paix [avec eux] et à qui ils doivent de respecter leur serment $»^{56}$. Mais il fallait procéder selon les usages établis entre les Andorrans et leurs voisins. En 1313, la

\footnotetext{
${ }^{50}$ Sur ce point les références sont très dispersées. nous en avons donné plusieurs exemples dans «Un modèle d'affrontement; les limites des communautés pyrénéennes », Frontières, 1994-1995, p. 23-46.

${ }^{51}$ P. OURLIAC, «L'ancien droit des Pyrénées », (art.cit.).

${ }^{52}$ Par l'énumération de ses confronts (C. BARAUT, Cartulari de la vall d'Andorra, Andorra, 1990, p. 117-118).

${ }^{53}$ Il livrait tout ce qu'il détenait en amont de Tavèrnoles (c'était le cas d'Arcavell qui n'était pas en Andorre). Mais, cette cession faite, il demanda aux Andorrans, et à eux seulement, de tenir son engagement en jurant fidélité à l'évêque. Enfin, il reconnut en contrepartie aux Andorrans leur adempramentum et son emparamentum. Sans entrer dans le détail, disons qu'il s'agissait de garantir aux Andorrans tous leurs usages du sol, d'Andorre ou d'ailleurs (C. BARAUT, Cartulari ..., (op. cit.), p. 158-160).

${ }^{54}$ Ibidem, t. 2, p. 165-167.

${ }^{55}$ Ibidem, t. 1, p. 324.

${ }^{56}$ Ibidem, p. 222.
} 
toute proche vallée d'Aneu se voyait reconnaître le droit de «traiter et faire la paix avec tous ses frontalers [...] selon leurs bonnes coutumes $»^{57}$. Dans la béarnaise vallée d'Aspe, le pouvoir du vicomte émergea du flou en 1247, quand les Aspois lui demandèrent de garantir la paix qu'ils avaient conclue avec les aragonais de $\mathrm{Jaca}^{58}$. En un mot, ces sociétés pyrénéennes fondaient leurs identités réciproques sur d'innombrables accords de paix, patzerias, lies et passeries ${ }^{59}$, et les forces politiques qui prétendaient à leur incorporation devaient, dans un premier temps, prendre en compte l'ordre social qui s'en dégageait. Déjà en 1096, Guitard Isarn de Caboet, en inféodant deux paroisses des Vallées, précisait à son vassal qu'il ne devait rien modifier des usages établis avec les Andorrans, mais encore, qu'il leur devait aide et conseil féodal en cas de querelle avec leurs voisins cerdans ou toulousains (c'est-à-dire du pays de Foix) ${ }^{60}$.

Cette tradition pyrénéenne de pacte et de paix explique les voies ambiguës de la normalisation juridique qu'obtinrent les seigneurs. Ainsi, les actes de 1162 et 1176 par lesquels l'évêque d'Urgell essaya de rationaliser ses rapports avec les Andorrans ne se présentent pas comme des jugements ou des règlements ; ce sont des convenientiae ${ }^{61}$, c'est-à-dire des pactes librement conclus entre les parties. Formellement, ce sont les Andorrans qui cédaient des droits au prélat, y compris juridictionnels. En 1275 encore, le comte de Foix pouvait accepter de recevoir des Andorrans, «par pure et parfaite donation entre vifs, [...] toutes les justices, civiles et criminelles, le merum et mixtum imperium, la pleine juridiction sur tous les hommes des Vallées ${ }^{62}$. En 1186, la cathédrale inféoda les vallées de Cabo, Sant Joan et Andorre, précisant que les deux premières étaient données avec la commande des châteaux et les ressorts qui en découpaient le territoire. Au contraire, le fief d'Andorre était consenti dans le strict respect des conventions rédigées et conclues avec les Andorrans. En parlant de «fief taillé dans les Vallées », Brutails ignorait cette incapacité de l'évêque à trancher dans le sol des Andorrans ; en guise de fief, la Mitre pouvait seulement donner les droits que lui avaient reconnus les Andorrans.

Schématiquement, deux ordres s'opposaient, celui des seigneurs féodaux avec leur pouvoir de contrainte - le ban (et son corollaire de bannissement) ou le districtum (qui prit le sens spatial que l'on sait) - et celui des communautés fondées sur les traités de paix et une même prétention à fixer les bornes signifiantes. En droit comme en fait, ces affrontements et ces concessions réciproques restaient asymétriques et au bénéfice toujours plus marqué des princes. Mais s'il y a une parcelle de souveraineté dans la capacité de manier les repères identitaires qui légitiment la contrainte légale, il devient patent que les communautés andorranes en maîtrisaient tous les termes. Formellement, les seigneurs étaient, dans un premier temps, traités comme des voisins. Certes, ils

\footnotetext{
${ }^{57}$ I. PUIG FERRETE, El monestir de Santa Maria de Gerri (segles XI-XV), t. 2, Barcelona, 1991, p. 211.

${ }^{58}$ P. OURLIAC et M. GILLES, Les Fors anciens de Béarn, Paris, 1990, p. 531-547.

${ }^{59} \mathrm{H}$. CAVAILLES, «Une fédération pyrénéenne sous l'ancien régime: les traités de lies et passeries », Revue Historique, CV, 1910, p. 1-34 et 241-276.

${ }^{60}$ C. BARAUT, Cartulari ..., (op. cit.), p. 145.

${ }^{61}$ P. OURLIAC, «La"convenientia" », Etudes d'histoire du droit privé offertes à Pierre Petot, Paris, 1959, p. 413-422.

${ }^{62}$ C. BARAUT, Cartulari ..., (op. cit.), p. 299-300.
} 
obtenaient des droits qui n'auraient jamais été consentis à une vallée adjacente, mais de la même façon qu'avec des frontaliers, les Andorrans exigeaient des contreparties, des garanties, et surtout, ils conservaient la maîtrise de l'ordre social interne. Par un enchaînement logique lumineux, l'accord de 1176 considère, après les litiges entre frontaliers, le cas des hommes d'Andorre contre lesquels l'évêque voudrait porter plainte : c'est aux hommes de leur paroisse, ou par défaut à «tout le peuple d'Andorre » qu'il revient de les contraindre à « faire droit » à la plainte épiscopale.

Le peuple d'Andorre était l'ensemble des hommes solidaires des serments prêtés à leurs frontaliers comme à leurs seigneurs. Le lien juridique n'était pas imposé mais contractuel, et de là venait leur façon si particulière de gérer les mécanismes de frontières. Cependant, on ne doit pas perdre de vue que ce sont les conditions politiques générales dans lesquelles était englobée Andorre qui survalorisaient ces limites-là (parce qu'elles devenaient la clef de leurs prérogatives les plus importantes). Comme le montre la mention des paroisses (comuns dans leur version communautaire), identité, communauté et contrainte se déclinaient autour de bien d'autres limites.

\section{Sur les principes du voisinage pyrénéen}

En effet, même si l'usage s'en est imposé depuis plus d'un siècle, il est réducteur sinon erroné de considérer les communautés comme l'assemblée des voisins, assimilés aux chefs de familles, chefs de maisons ou chefs d'exploitations agricoles. Si l'on entend par voisinage ou droit de voisinage, l'ensemble des règles et des pratiques qui autorisent l'accès aux terres collectives et la participation aux prises de décisions politiques qui concernent la collectivité, on peut affirmer que, dans les Pyrénées médiévales, l'unité domestique n'en constituait nullement le pivot. Ainsi doit-on relever qu'en maints endroits de la chaîne se sont dégagées deux catégories de maisons, celles qui avaient une entière jouissance des communaux et qui monopolisaient le pouvoir décisionnel, et celles qui avaient un profit moindre des ressources collectives et qui étaient exclues de la vie politique (la justification, tant vernaculaire que savante, qui avance l'ancienneté des premières est purement idéologique ${ }^{63}$ ).

Il n'est possible de comprendre ce voisinage qu'en respectant ses contours. Lorsqu'une vallée faisait la paix, elle devenait responsable des agissements de toutes les communautés immédiatement inférieures, desquelles, par ailleurs, elle était mandataire. Mais cela se répétait à tous les échelons communautaires. Chaque groupe avait ses ressources et ses limites à défendre, un droit de contrainte en corollaire, et chacun était comme une fédération des communautés inférieures. C'est pourquoi la constitution de ces collectivités doit se lire en deux temps analytiques.

Les conflits et les paix, les négociations et les arbitrages, les accords et les serments collectifs déployaient leurs scènes fondatrices autour de toutes les

\footnotetext{
${ }^{63}$ A tout le moins, cela pourrait se montrer pour Andorre, voire pour la vallée d'Aneu malgré l'explication démographique proposée dans J. M. BRINGUE i PORTELLA, "Comunitats, senyors i societat rural al Pallars Sobirà », Mélanges de la Casa de Velázquez, Tome XXIX-2, 1993, p. 135-151.
} 
lisières territoriales, pour le bornage de minuscules hameaux comme pour les guerres entre vallées. A l'instar d'Andorre face aux vallées voisines, chaque communauté était un corps politique qui se construisait dans ses affrontements et dessinait ainsi son territoire. Ces groupes s'identifiaient par l'usage en commun de pâturages, de bois, de taillis, de ruisseaux ... et se structuraient dans les garanties (base des contraintes internes) qu'ils donnaient aux groupes voisins, ou dans les droits communs à l'utilisation des biens d'autrui sur lesquels ouvraient leurs pactes. La capacité des quarts andorrans ou des vicqs barégeois à se remodeler, à changer d'assises foncières parce que se modifiaient les groupes sociaux qui les fondaient, est une excellente illustration de ces dynamiques à l'œuvre dans la manipulation des limites territoriales ${ }^{64}$.

Mais ce mouvement emportait, de par sa répétition pyramidale, les germes de son verrouillage. Tout règlement de paix imposait à chaque groupe de choisir un mode de représentation, une structure de discipline, des moyens de contraintes, et, par rétroaction, figeait l'identité politique des communautés inférieures. Cette solidarité, passée aux cribles de l'enchevêtrement des enjeux, de la démultiplication des limites et de la superposition des instances d'arbitrage, bridait l'expression des intérêts particuliers. L'explosion sociale, ou la contestation de cet ordre, étaient peu probable parce que le particulier ne s'opposait pas au général, parce qu'il ne s'identifiait ni à l'individu ni à un groupe précis mais se diluait dans une hiérarchie de corps politiques qui lui donnaient les moyens de son existence; le conflit était d'autant moins pertinent que, corrélativement, l'autre (maison, hameau, quart, paroisse ...) devenait mécaniquement solidaire de soi-même quand les frictions se déplaçaient vers la limite d'une communauté plus large. La cohésion du système venait de ce que la charge d'identification et de contrainte véhiculée par ces limites ne se focalisait pas sur l'une d'entre elles, mais se diluait, se diffusait pour innerver tout le sol et toute la société andorrane.

Cette lecture permet une version homogène du voisinage. A l'image de l'ensemble de la vallée, le groupe des voisins à l'échelon le plus élémentaire est fait de ceux qui obtiennent un terroir propre en affrontant des groupes semblables, mais surtout de ceux qui en contrepartie imposent une discipline à leur groupe, ceux qui distribuent les responsabilités, ceux qui font l'entité et l'identité politique qui compose le hameau : la maison de plein droit. Garants de la paix avec le hameau voisin ou vis-à-vis des communautés plus larges, ces voisins sont ceux que le hameau a jugé les plus aptes à défendre ses intérêts, ceux qui ont par conséquent le pouvoir d'arbitrer les conflits internes. Leurs maisons apparaissent ainsi comme la représentation du cercle le plus étroit des communautés superposées. De la même façon, elles se forgent dans les concessions réciproques d'un territoire propre (vaine pâture), dans leurs affrontements (des litiges de bornage aux arbitrages politiques), dans la solidarité qu'imposent ces conflits (l'acceptation d'une discipline domestique, ou la dépendance d'une grande maison pour les familles plus modestes), dans la cristallisation d'une autorité interne (le voisin par excellence, c'est-à-dire le chef de maison). La possession de biens-fonds privés ne faisait pas le voisin, mais la valeur de ses terres lui faisait des obligés ; elles le désignaient aux communautés comme leur représentant

${ }^{64}$ R. VIADER, « Un modèle d'affrontement ... », (art.cit.), p. 30-36. 
naturel. Sous cet angle, la césure hiérarchique qui s'instaura entre les unités domestiques est parfaitement logique ${ }^{65}$.

De la maison à la vallée, l'ordre social d'Andorre (et par conséquent les principaux repères de l'identité) reposait donc sur l'inlassable répétition d'une scène d'affrontement et de pacte, déclinée sur une myriade de limites territoriales, depuis le mur mitoyen jusqu'aux frontières du pays. Cette conception du droit et de l'identité permettait aux Andorrans de manipuler assez efficacement tout type de limites territoriales, parce qu'elle ne procédait pas d'une duplicité, d'une confusion dans le jeu des appartenances identitaires, mais de leur propension à considérer toute frontière comme le lieu d'un contrat ${ }^{66}$.

Cependant, l'on objecterait volontiers que cela n'explique pas le corps de règles et de pratiques coutumières qui plaçait le cap de casa (chef de famille et de maison) andorran au centre de toute la vie coutumière des Vallées, comme des Pyrénées en général. Ce serait oublier quatre choses essentielles.

1/ La nature des affrontements, et les pactes qui en résultaient, modelaient les formes prises par la contrainte que s'imposaient les communautés.

2/ La puissance des princes modifiait selon ce principe l'ordre des communautés. Elle valorisa l'ensemble de la vallée après les paréages, les paroisses au $\mathrm{XI}^{\mathrm{e}}$ siècle, et les quarts prirent leur essor vers la fin du XII ${ }^{\mathrm{e}}$.

3/ Les princes et leurs juristes ont édifié les textes qui nous servent à jauger de la légalité, des institutions et de la coutume. Les références employées ne sont pas celles des Andorrans, même s'ils adaptèrent leurs logiques sociales aux façons de cette énonciation juridique.

4/ C'est Brutails, pourfendeur de toute indépendance des communautés andorranes, qui a rédigé la coutume d'Andorre.

\section{4/ La maison-famille, fossile juridique d'une frontière disloquée}

Sous son visage désormais classique, la maison-famille des Pyrénées se présente comme le socle de toute relation sociale, la référence absolue par laquelle transitent l'identité des personnes, les formes de la succession et de l'alliance, l'organisation de la production et les rapports d'autorité67. Cette

\footnotetext{
${ }^{65}$ Cette lecture du phénomène induit, en outre, une puissante continuité entre ces chefs de maisons et les boni homines du droit romano-wisigothique et de la société catalane des $\mathrm{IX}^{\mathrm{e}}$ et $\mathrm{X}^{\mathrm{e}}$ siècles, « régulateurs des rapports sociaux [...] investis d'une fonction judiciaire, soit qu'ils règlent à l'amiable des litiges entre villageois, soit qu'ils participent aux plaids publics... » (P. BONNASSIE, La Catalogne du milieu du $X^{\circ}$ à la fin du XI siècle, croissance et mutations d'une société, Toulouse, 1975-1976, p. 310).

${ }^{66}$ Cependant, dans le cas des droits de douanes, ces conceptions n'allaient pas, effectivement, sans duplicité. En effet, lorsqu'ils étaient directement concernés, ils savaient parfaitement contrecarrer les mécanismes de sas. Ainsi interdisaient-ils à leurs voisins de faire paître sur leur terre, à raison de baux à cheptel, des bêtes qui ne seraient pas la propriété de ces voisins mais de gens contre qui les Andorrans seraient en guerre (I. BAIGES et M. FAGES, Diplomatari..., (op. cit.) p. 26-29).

${ }^{67}$ Depuis Le Play (L'organisation de la famille selon le vrai modèle signalé par l'histoire de toutes les races et de tous les temps, Paris, 1871), la bibliographie sur cette question est devenue
} 
omnipotence puisait sa force dans les pratiques et les règles qui assujettissaient le trajet des individus à la perpétuation d'un ensemble foncier. On prétendait en outre, par un intéressant bouclage logique, que la succession préciputaire, l'inaliénabilité des biens-fonds ou le droit prioritaire pour les chefs de maison de racheter les lopins vendus par des ancêtres nécessiteux, provenaient d'une certaine conception de la famille et de la propriété, ancrée dans la nuit des temps pyrénéens $^{68}$. De cela, Brutails avait donné une variante andorrane conforme à l'esprit général.

Sans s'appesantir sur les erreurs ou les lacunes qui ont forgé ce modèle, il faut noter que, dans cette perspective, il n'y a rien de commun entre les maisons et les principes du voisinage. En un beau paradoxe, ces conceptions que l'on voudrait ordonnatrices de toute une vie sociale pyrénéenne n'expliquent aucun des traits particuliers du régime des communautés. A rebours de cette doctrine et à partir du dossier andorran, nous voudrions montrer que les institutions de voisinage précédèrent et informèrent le modèle domestique, puis, proposer de lire le masque foncier de la maison comme le résultat d'une conversion juridique.

\section{Les origines du modèle ...}

Tous les indices dont nous disposons montrent que, jusqu'au XIII siècle, les règles successorales entravaient la dévolution entière d'un patrimoine foncier à un seul héritier. La pratique prolongeait le droit wisigothique qui stipulait le partage égalitaire entre les enfants. Certes, il était possible d'avantager l'un d'eux en lui octroyant une melioratio (un tiers du total de l'héritage) en plus d'une part égale à celles de ses frères dans le partage des deux tiers restant. C'est ce cas de figure que l'on rencontre généralement dans les textes du XIII ${ }^{\mathrm{e}}$ siècle $^{69}$; il prouve autant une volonté de se soustraire au partage égalitaire que la prégnance de ce principe successoral. Loin des images traditionnelles, les biens-fonds ne sont pas issus d'une répartition définitive mais de partages successoraux pluriséculaires ; ils ne sont pas figés par inaliénabilité mais recomposés sans cesse au gré de nombreuses transactions ; ils n'inscrivent pas naturellement leur détenteur dans une communauté territoriale puisqu'ils peuvent être disséminés dans plusieurs hameaux, plusieurs villages. Si s'ébauche parfois la volonté de transmettre l'essentiel d'une exploitation, l'on est bien loin encore des formes de la casa.

Les communautés, en revanche, exerçaient déjà leur emprise, contrôlaient l'accès au ressources collectives, et arbitraient les conflits entre voisins. Le cas le plus intéressant est celui des quarts qui semblent exister depuis aussi longtemps que les comuns et avoir connu un regain d'activité au cours du XIII siècle. Construits autour d'un ou de plusieurs hameaux, on peut être certain qu'ils ne

pléthorique. Pour une première approche, on peut consulter G. AUGUSTINS, « Un point de vue comparatif sur les Pyrénées », Les Baronnies des Pyrénées, I. CHIVA et J. GOY (éd), Paris, 1986, p. 201-214.

${ }^{68}$ Pour une critique de ces conceptions : L. ASSIER-ANDRIEU, « Le Play et la famille-souche des Pyrénées : politique, juridisme et science sociale », Annales; E. S. C., n 3, mai-juin, 1984, p. 495-512 ; «L'esprit de la maison pyrénéenne », Los Pirineos. Estudios de antropologia social e historica, Madrid, 1986, 95-109.

${ }^{69}$ Par exemple, C. BARAUT, Cartulari ..., (op. cit.), t. 2, p. 110. 
sont le résultat d'aucune mesure fiscale, administrative ou juridique des pouvoirs politiques qui dominaient Andorre, qu'ils ne résultent pas de concessions foncières, qu'ils ne furent dictés ni par une nucléarisation de l'habitat, ni par des nécessités sylvo-pastorales. La capacité qu'ils avaient de modifier leur composition et leurs contours en est la meilleure illustration.

Cette qualité des quarts, les pratiques successorales et la composition des biens privés du XIII ${ }^{\mathrm{e}}$ siècle montrent que le système de la maison ne dérive pas de règles archaïques, et que l'accès aux ressources collectives n'est pas la conséquence mécanique d'une insertion évidente des biens privés dans un ensemble présupposé, écologique ou politique. Au contraire, sans évoquer à nouveau ce qui relie le rôle des voisins à toutes les formes de communautés (la gestion des limites, les contraintes des pactes et la cristallisation d'autorités), l'on peut rappeler cette fonction d'arbitrage qui, comme les règles de succession, se place dans une puissante continuité avec le droit wisigothique. Il faut surtout noter que le décalage qui se fait jour entre la maturation des quarts et la mise en place du système de la maison rend visible une distorsion cruciale.

Partout où la maison domine l'architecture sociale, le nom de maison prend le pas sur les patronymes. Dans l'Andorre du XIII ${ }^{e}$ siècle, les règles anthroponymiques restent floues et mêlent des usages très divers. Cependant, la propension des Andorrans à se désigner par le nom d'un hameau est significative. Les actes de la pratique peuvent mentionner une dizaine de personnes, réduire le nom de certains à une initiale tout en prenant soin de préciser, pour chacun, le nom de son hameau ou de son quart. L'effet est saisissant lorsqu'ils sont tous du même lieux ${ }^{70}$. Il ne s'agit plus d'une façon de se différencier, mais bel et bien d'un repère essentiel de l'identité, d'une façon de faire valoir un droit, au même titre que le nom de maison ailleurs, ou en Andorre plus tard. C'était la communauté qui faisait le voisin et non la seule détention d'un patrimoine privé.

Ainsi doit-on comprendre les tentatives d'évitement du partage successoral et le succès, au XIV ${ }^{\mathrm{e}}$ siècle, des formules notariales qui permettaient (sans l'imposer) la dévolution du patrimoine à un héritier unique ${ }^{71}$. Le scénario des affrontements désignait les plus riches comme les voisins par excellence, les chefs d'une micro-communauté de fermes dépendantes. L'économie agropastorale des Pyrénées assurait à ceux qui disposaient de la plus grande surface de terres privées un bénéfice supérieur des ressources collectives ${ }^{72}$. En renonçant à leur part au profit d'un héritier unique (comme l'on procédait au XIV ${ }^{\mathrm{e}}$ siècle) ses frères conservaient à la maison son pouvoir économique et son statut politique (lesquels se renforçaient alors que le démembrement en plusieurs exploitations signifiait la perte de ces deux pouvoirs). Après plusieurs générations, l'inégalité des maisons ne pouvait être que plus marquée et la qualité de voisin s'attachait à quelques familles. L'autorité de leurs chefs devait alors paraître incontestable de l'extérieur comme de l'intérieur. Cependant, il ne faut pas oublier que la renonciation des exclus de l'héritage ne semble avoir revêtu aucun caractère d'obligation juridique. La condition de voisin pouvait être liée à la richesse

\footnotetext{
${ }^{70}$ Exemple très significatif : C. BARAUT, Cartulari ..., (op. cit.), t. 2, p. 121-122.

${ }^{71}$ I. BAIGES et M. FAGES, Diplomatari..., (op. cit.) p. 31-33 et 80-81

72 L. ASSIER-ANDRIEU, Coutume et rapports sociaux. Etude anthropologique des communautés rurales du Capcir, Paris, 1981, p. 99.
} 
foncière, elle n'en demeurait pas moins soumise à la logique de confrontation en cascade des communautés.

\section{... et les voies de sa conversion}

En 1419, les co-seigneurs accordèrent aux Andorrans le droit d'élire des représentants permanents à l'origine du Conseil Général des Vallées, ou Conseil de la Terre ${ }^{73}$. En même temps qu'elle la pérennisait, cette institutionalisation ôtait beaucoup de sa nature subversive à la grande communauté des Vallées. Elle ne se définissait plus dans l'affrontement des frontaliers et des princes, mais comme un privilège qui, à la manière de l'enquête de 1347, liait l'identité d'Andorre au pouvoir des co-seigneurs.

Pendant tout l'âge moderne, si l'ordre des communautés se maintint, le sens des conflits territoriaux fut largement dévitalisé par le bouclage du jeu politique et économique. En effet, jusqu'en 1763, la vie des Vallées fut tenue en main par à peu près cent quatre-vingts personnes, les chefs des maisons appelées focs (feux), qui, à ce titre, selon un schéma déjà entrevu, prenaient toutes les décisions d'intérêt collectif, contrôlaient l'usage des terres communes et jouissaient d'importants privilèges sur les ressources collectives ${ }^{74}$. La préservation du patrimoine foncier restait pertinente mais n'était plus ni nécessaire ni suffisante $^{75}$. La démultiplication des limites et de leur gestion n'avaient plus qu'un rôle très subsidiaire.

A cette époque, les chefs de focs renoncèrent à leurs privilèges économiques en contrepartie d'une participation des autres chefs de maisons, les casalers, à l'impôt du redre. Toutes les nouvelles unités agricoles devenaient ainsi, sur le plan économique, des ayants droit à part entière, et leur prolifération menaçait, sinon d'épuiser les ressources des communaux, de limiter le parti qu'en tiraient les maisons existantes. Vingt ans après, dit-on, il fut déclaré par décret que toute vente d'immeuble était, en Andorre, présumée à carta de gracia $^{76}$. Cela signifiait qu'à tout moment une terre pouvait être rachetée par la maison qui l'avait un jour vendue. Sans connaître les motivations immédiates ou plus profondes de cette décision, on peut croire qu'elle était très liée à ce nouveau contexte. Qui, mieux que les plus anciennes et les plus grandes maisons, disposait de ces titres de vente et des liquidités permettant de bloquer le marché foncier, et d'interdire ainsi la naissance ou le développement d'exploitations ?

Un demi-siècle après les réformes amorcées en 1763, Pierre Roch de Roussillou, viguier d'Andorre pour la France, décrivait des pratiques d'héritage que n'eût pas désavouées Brutails. Mais il ajoutait que cet usage ne valait que par

\footnotetext{
${ }^{73}$ F. VALLS TABERNER, Privilegis $i$ ordinacions de les valls pirinenques, Barcelona, 1920, p. 477-481.

${ }^{74}$ E. LOPEZ et J. PERUGA, Diplomatari ..., (op. cit.), p. 17.

${ }^{75}$ Le nombre et l'identité des focs étant figés, les casalers pouvaient se multiplier (d'eux-mêmes ou par l'installation du frère de l'héritier d'une maison de plein droit) les avantages des décisionnaires n'en souffrait guère. A l'inverse, on peut imaginer qu'un casaler très riche ne pouvait bénéficier des pâturages en quantité suffisante pour faire fructifier son exploitation, et que mieux valait la diviser.

${ }^{76}$ P. OURLIAC, « La réforme ... », (art. cit.), p. 318.
} 
consensus ; si un enfant exclu avait voulu contester les volontés de son père, il aurait pu obtenir une part d'héritage ${ }^{77}$. Cela, disait-il, était si peu conforme à l'esprit du pays qu'on l'avait vu deux fois seulement depuis Charlemagne. Le système de la maison n'était pas pour lui, ni pour les Andorrans, inscrit dans une loi de la terre, dans une coutume locale. Il était l'effet d'une pratique contractuelle admise comme une norme sociale, et non comme un impératif juridique. Néanmoins, la manière dont on évoquait les possibles fragmentations de l'unité domestique confirme, comme le décret sur les ventes d'immeubles, qu'elles étaient devenues socialement indésirables.

En 1866, une nouvelle réforme mettait fin à la distinction entre focs et casalers, et donnait le pouvoir à tous les chefs de maison. Tous devenaient donc acteurs politiques et membres de plein droit des communautés. En apparence, le voisinage, dans ses manifestations élémentaires, retrouvait toute sa vigueur. En fait, l'ordre des maisons était verrouillé par les règles successorales. Une mutation radicale s'opérait dans les Vallées : on n'était plus un voisin par l'effet de structures de voisinages mais parce qu'on était chef de famille et propriétaire, héritier d'une maison andorrane. Quand, vers 1900, Brutails rédigea la Coutume d'Andorre, les sages qu'il consulta semblent avoir passé sous silence les possibilités légales de partage et omis de narrer ses deux occurrences depuis le temps de Charlemagne.

A ce stade, s'est opéré un renversement complet des principes de l'ordre social. Le corps politique d'Andorre n'est plus composé d'une hiérarchie de communautés unies par des contrats de paix et déterminant librement leurs territoires. Il n'est même plus une cristallisation de ces hiérarchies. Il est un Etat de caps de casa, seuls autorisés à être propriétaires terriens. Dans cette optique, il est clair que les coutumes qui protègent les maisons ont pour dessein politique d'immobiliser la composition et la hiérarchie de l'ensemble citoyen. Devenue l'ultime rouage efficace des structures de voisinage, la maison apparaît comme un dernier refuge. Elle assume sous les couverts du droit privé toute la charge politique qui disparaît avec l'enchâssement des communautés, et la foison signifiante des limites territoriales anciennes.

On comprend, dès lors, que Brutails ait eu l'impression de découvrir un avatar fidèle de la propriété quiritaire. Mais, en l'interprétant comme le fruit exclusif d'une certaine idée de la famille, il dissimulait pour longtemps ses origines et sa nature politique. Pour celui qui niait toute indépendance juridique des communautés andorranes, il était plus facile de lire la maison comme un droit privé que d'y retrouver une contrainte de type public.

Cette traversée de la Question d'Andorre nous a dévoilé la capacité des frontières à identifier les sociétés pour que disparaissent les origines et les contradictions de l'ordre social qui s'y impose. Elle nous a montré comment les Andorrans savaient en faire de même avec toute limite territoriale, y compris les bornes d'une propriété. Ainsi s'explique l'aisance avec laquelle ils manœuvrèrent tant de frontières qui auraient dû s'imposer à eux. A la raison des princes ou des

${ }^{77}$ P. ROCH de ROUSSILLOU, De l'Andorre, Toulouse, 1823, p. 25. 
Etats, à la raison de l'écrit ou du droit, ils opposaient des catégories floues ou l'empire de la coutume orale. Brutails parlait de «l'idée très obscure de la légalité dans les cerveaux andorrans» de «vague perpétuel», d'une « universelle confusion» ou d'une «perpétuelle équivoque ». Il ne parvint pas à imposer la souveraineté de la France mais donna aux Andorrans les moyens de pérenniser un ordre pluri-séculaire. Il ne parvint pas à imposer sa frontière, et ne vit pas que les Andorrans logeaient dans sa Coutume les limites résiduelles d'une frontière démultipliée.

Trente ans après Brutails, le vieil ordonnancement des communautés en cascade ne se maintenait plus, en apparence, que dans le découpage électoral ; chacun des six comuns élisait ses conseillers de la Vallée. En revanche, les désirs d'indépendance qui se manifestaient témoignent d'une conception nationale en pleine expansion. Les événements de 1933 se soldèrent par l'octroi du droit de vote à tous les Andorrans âgés de plus de vingt cinq ans. Le système politique des maisons s'effondrait. Les limites significatives n'étaient plus celles des propriétés privées mais les frontières d'Andorre. Elles ne le restèrent pas longtemps. En 1937, Andorre comptait $12,5 \%$ d'étrangers sur son sol, et $65,4 \%$ en 1967. Seuls les Andorrans étaient citoyens et les conditions d'accès à cette nationalité discutée étaient très restrictives ${ }^{78}$. Nous retiendrons la seule façon de devenir immédiatement et automatiquement andorran : épouser une pubilla, c'est-à-dire l'héritière d'une maison. Cette résurgence politique, par les canaux du droit privé, des anciennes structures d'identification, du voisinage et de ses mille fronts, doit être lue, par la recherche scientifique, comme une mise en garde. Les frontières d'Andorre ne sont pas nécessairement là où on les attend. Les sommes importantes investies par le gouvernement andorran dans la recherche d'un identité traditionnelle, et l'accent placé avec Brutails sur la culture de la casa et le modèle de la maison ne sont pas des opérations neutres. Les frontières pulvérisées survivent au cœur d'Andorre. Quant à leur vêture contemporaine, c'est là une autre enquête ${ }^{79}$.

\footnotetext{
${ }^{78}$ P. OURLIAC, « La réforme ... », (art. cit.), p. 3107-316.

${ }^{79}$ Nous renvoyons, notamment, à l'article présenté dans ce même numéro par Joan Becat.
} 
